\title{
ANALISIS SISTEM PENGELOLAAN REKAM MEDIS RAWAT INAP DI RUMAH SAKIT ISLAM JEMURSARI SURABAYA
}

\author{
Rizqiyah $^{1}$, Ernawaty ${ }^{2}$ \\ ${ }^{1}$ Fakultas Kesehatan Masyarakat, Universitas Airlangga, Surabaya \\ ${ }^{2}$ Fakultas Kesehatan Masyarakat, Universitas Airlangga, Surabaya \\ E-mail: Rizqiyah2002@yahoo.com
}

\begin{abstract}
Based on Permenkes No. 749 a / Menkes / Per / XII / 1989 about medical records, that any health services, including hospitals are required to held medical records. Medical records management at the hospital used to support the achievement of orderly administration in an effort to achieve the goal of hospitals to improve the quality of health care in hospitals. One of the standards that must be met by hospitals is related to the quality of medical records (Depkes RI, 1994). One of the issues raised in the Islamic Hospital Jemursari Surabaya related to medical records that have not yet managed properly. The purpose of this research was to analyze the data management system in place of registration of inpatients, assembling activities, coding, analising and reporting until filling activities at the Medical Record Unit Islamic Hospital Jemursari Surabaya. This research uses descriptive qualitative research methods. The results showed that there are shortcomings in the system of registration of inpatients, the implementation of assembling, coding implementation, implementation analising and reporting, as well as the implementation of the filling .
\end{abstract}

Keywords : hospital, inpatient, medical record 


\begin{abstract}
ABSTRAK
Berdasarkan Permenkes No 749a/Menkes/Per/XII/1989 tentang rekam medis, bahwa setiap pelayanan kesehatan termasuk rumah sakit diwajibkan untuk menyelenggarkan rekam medis. Pengelolaan rekam medis di rumah sakit digunakan untuk menunjang tercapainya tertib administrasi dalam rangka upaya mencapai tujuan rumah sakit meningkatkan mutu pelayanan kesehatan di rumah sakit. Salah satu standar yang harus dipenuhi oleh rumah sakit adalah terkait kualitas rekam medis (Depkes RI,1994). Salah satu permasalahan yang terjadi di Rumah Sakit Islam Jemursari Surabaya terkait dengan rekam medis yang belum belum dikelola dengan baik. Tujuan penelitian ini adalah menganalisis sistem pengelolaan data di tempat pendaftaran pasien rawat inap, kegiatan assembling, coding, analising and reporting sampai dengan kegiatan filling di Unit Rekam Medis Rumah Sakit Islam Jemursari Surabaya. Jenis penelitian ini menggunakan metode penelitian deskriptif kualitatif. Hasil penelitian menunjukkan bahwa masih terdapat kekurangan dalam sistem pendaftaran pasien rawat inap, pelaksanaan assembling, pelaksanaan coding, pelaksanaan analising and reporting, serta pelaksanaan filling.
\end{abstract}

\title{
Keywords : Medical record,Rawat Inap, Rumah Sakit
}

\section{PENDAHULUAN}

Rumah sakit adalah salah satu organisasi pelayanan kesehatan yang padat modal dan padat karya, sehingga harus dikelola secara efektif dan efisien. Dalam pelaksanaaannya rumah sakit memiliki tugas memberikan pelayanan kesehatan perorangan secara paripurna. Rumah sakit menyelenggarakan kegiatan pelayanan berupa pelayanan rawat jalan, rawat inap, gawat darurat, rujukan yang mencakup pelayanan rekam medis dan penunjang medis yang dapat dimanfaatkan untuk pendidikan, pelatihan, dan penelitian bagi para tenaga kesehatan. Di era JKN ini setiap rumah sakit diharuskan untuk mengikuti akreditasi RS yang bertujuan untuk meningkatkan kualitas layanan yang diberikan. Berdasarkan Permenkes No 749a/Menkes/Per/XII/1989 tentang rekam medis, bahwa setiap pelayanan kesehatan termasuk rumah sakit diwajibkan untuk menyelenggarkan rekam medis.

Rekam medis merupakan bukti tertulis mengenai proses pelayanan yang diberikan kepada pasien oleh dokter dan tenaga kesehatan lainnya yang dapat dipertanggungjawabkan. Rekam medis digunakan dalam pengelolaan dan perencanaan fasilitas dan pelayanan kesehatan. Selain itu juga dapat digunakan untuk penelitian medis dan kegiatan statistik pelayanan dikala pasien datang kembali ke tempat pelayanan kesehatan. Pengelolaan rekam medis di rumah sakit digunakan untuk menunjang tercapainya tertib administrasi dalam rangka upaya mencapai tujuan rumah sakit, yaitu peningkatan mutu pelayanan kesehatan di rumah sakit. Salah satu standar yang harus dipenuhi oleh rumah sakit adalah terkait kualitas rekam medis (Depkes RI,1994).

Rumah Sakit Islam Jemursari merupakan salah satu dari 3 instansi yang dikelola oleh Yayasan Rumah Sakit Islam Surabaya (YARSIS). Rumah sakit ini termasuk dalam tipe B dan sudah lulus akreditasi 16 pelayanan. Salah satu permasalahan yang terjadi di rumah sakit ini terkait dengan rekam medis yang belum belum dikelola dengan baik. Tujuan penelitian ini adalah menganalisis sistem pengelolaan rekam medis rawat inap di Unit Rekam Medis Rumah Sakit Islam Jemursari Surabaya.

\section{METODE PENELITIAN}

Jenis penelitian ini menggunakan metode penelitian deskriptif kualitatif, yaitu penelitian yang menggambarkan dan mendeskripsikan pengolahan data rekam medis rawat inap, sistem pengolahan data rekam medis rawat inap dan kendala pengolahan data rekam medis rawat inap di 


\section{Analisis Sistem Pengelolaan Rekam Medis Rawat Inap ... | RIZQIYAH}

Rumah Sakit Islam Jemursari Surabaya. Pengambilan data dilakukan pada bulan Februari sampai Maret 2016, menggunakan cara dengan observasi dan wawancara mendalam. Tehnik triangulasi dilakukan dengan membandingkan hasil wawancara dengan data hasil observasi. Wawancara dilakukan kepada koordinator unit rekam medis dan petugas yang bertanggung jawab dibagian tempat pendaftaran pasien rawat inap (TPPRI); (assembling; coding and indexing; analising and reporting; dan filling).

\section{HASIL PENELITIAN DAN PEMBASAN}

\section{A. Pengolahan Data di Tempat Pendaftaran Pasien Rawat Inap di Rumah Sakit Islam Jemursari Surabaya}

Gambaran pengelolaan data di tempat pendaftaran pasien rawat inap (TPPRI) di RumahSakit Islam Jemursari Surabaya sudah menggunakan pengolahan data elektronik yaitu pasien baru yang datang harus membawa surat pengantar rawat inap yang kemudiand imasukkan kekomputer. Untuk dicetak kartu masuk rumah sakit (MRS).Setelah selesai maka keluarga pasien memeriksa kesesuaian data pasien. Jika sudah sesuai maka keluarga pasien kembali ke UGD atau poli untuk menunggu ruangan disiapkan oleh perawat. Untuk pasien lama yang akan rawat inap kembali maka menunjukkan kartu identitas pasien RSI Jemursari untuk mencari berkas rekam medis yang sudah tersimpan dibagian filling. Berikut ini adalah flow chart dari pendaftaran pasien rawat inap di RSI Jemursari:

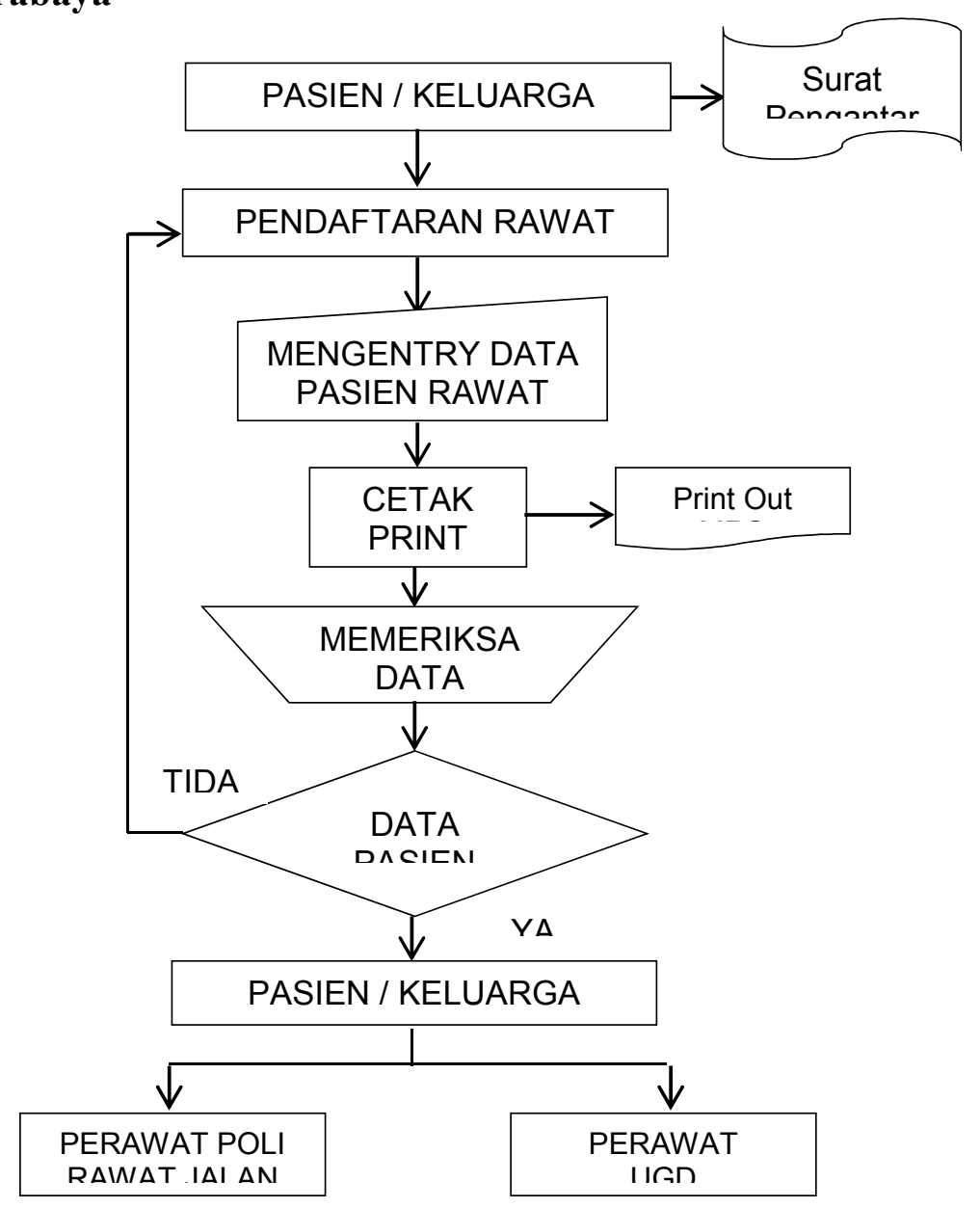

Sumber: Pedoman Pengorganisasian Unit Informasi dan Kerjasama Rumah Sakit Islam Jemursari Surabaya

Gambar 1 Alur Pendaftaran Pasien Rawat Inap di RSI Jemursari Surabaya 
Bagian TPPRI berada dibawah Unit Informasi dan Kerjasama, pada pendaftaran pasien rawat inapyang terdiri dari petugas admisidan petugas rekam medis.Petugas rekam medis yang ada di TPPRI bertugas dalam mengerjakan sensus harian dan Surat Keterangan Medis (SKM). Sedangkan petugas admisi bertugas dalam meneliti kelengkapan administrasi yang diperlukan dalam pendaftaran pasien rawat inap.

\section{B. Pelaksanaan Assembling Berkas Rekam Medis Rawat Inap di Unit Rekam Medis Rumah Sakit Islam Jemursari Surabaya}

Assembling merupakan proses pengecekan kelengkapan dari berkas rekam medis. Proses assemblingdilakukan setelah pasien keluar dari rumah sakit. Petugas rekam medis akan berkeliling ke ruangan setiap dua hari untuk mengambil berkas rekam medis pasien. Kegiatan assembling di Unit Rekam Medis Rumah Sakit Islam Jemursari belum berjalan dengan baik. Hal ini terlihat dari masih banyaknya dokumen rekam medis yang belum terisi dengan lengkap dan belum tertata dengan rapi. Pada tahap ini sering terjadi kesalahpahaman antara petugas rekam medis dan tenaga kesehatan terkait kelengkapan pengisian berkas rekam medis.

\section{Pelaksanaan Coding dan Indexing Berkas Rekam Medis Rawat Inap di Unit Rekam Medis Rumah Sakit Islam Jemursari Surabaya}

Gambaran pelaksanaan coding di Unit Rekam Medis Rumah Sakit Islam Jemursari Surabaya masih belum berjalan dengan optimal. Pelaksanaan coding dilakukan oleh seorang petugas dari lulusan rekam medis. Berbagai hambatan yang terjadi di pelaksanaan coding salah satunya terkait ketidakjelasan tulisan dokter terhadap diagnosa penyakit pasien sehingga hal ini menghambat petugas coding dalam memasukkan kode penyakit. Menurut Peraturan Menteri Kesehatan Republik Indonesia Nomor 377/MENKES/PER/III/2007 tentang Uji
Kompetensi Perekam Medis yaitu: Klarifikasi dan kodefikasi penyakit, masalah-masalah yang berkaitan dengan kesehatan dan tindakan medis, yaitu perekam medis mampu menetapkan kode penyakit dan tindakan dengan tepat sesuai klasifikasi internasional tentang penyakit dan tindakan medis dalam pelayanan dan manajemen kesehatan meliputi nomor kode diagnosis, fungsi indeks penyakit, registrasi, aplikasi ICD-10, penyediaan informasi morbiditas \& mortalitas, manfaat data diagnosis dalam klaim asuransi, etika coding.

\section{Pelaksanaan Analising dan Reporting Berkas Rekam Medis Rawat Inap di Unit Rekam Medis Rumah Sakit Islam Jemursari Surabaya}

Pengambilan berkas rekam medis di Rumah Sakit Islam Jemursari dilakukan oleh petugas analisa. Batas maksimal waktu pengambilan $2 \times 24$ jam setelah pasien selesai melakukan perawatan dan dinyatakan keluar dari rumah sakit. Berkas rekam medis nantinya akan di analisa untuk dimasukkan ke komputer.

Berkas rekam medis yang dianalisis untuk dimasukkan ke komputer terlebih dahulu di teliti kelengkapannya oleh petugas assembling. Nantinya petugas analisa akan mengelompokkan berkas rekam medis medis menjadi 3 yaitu berkas rekam medis yang lengkap, berkas rekam medis yang kembali ke ruangan untuk diisi oleh perawat atau yang biasa disebut dengan istilah retur dan berkas rekam medis untuk dokter sebagai pekerjaan rumah (PR).

Rekam medis retur biasanya rekam medis yang belum diisi lengkap oleh perawat sehingga akan dikembalikan lagi ke masing-masing ruangan untuk dilengkapi sampai lengkap 100\%. Sedangkan rekam medis PR adalah sebutan untuk berkas rekam medis yang masih belum diisi lengkap oleh dokter. Hal ini disebabkan oleh kesibukan dokter sehingga tidak sempat untuk mengisi resume rekam medis. Sistem ini diterapkan di Unit Rekam Medis Rumah Sakit Islam Jemursari untuk 
meningkatan pengisian berkas rekam medis guna menunjang proses akreditasi RS.

Pelaporan berkas rekam medis rawat inap di Rumah Sakit Islam Jemursari dilakukan ke pihak internal dan eksternal rumah sakit. Pelaporan internal dilakukan setiap bulan yang berasal dari sensus harian dan kunjungan dari setiap ruangan. Hal ini untuk mengetahui indikator kinerja instalasi rawat inap yang terdiri dari BOR, TOI, ALOS, BTO dan lama hari perawatan. Keseluruhan indikator tersebut akan dijadikan masukan untuk pengambilan keputusan di tingkat manajemen. Sedangkan laporan eksternal yang diberikan kepada:

1. Dinas Kesehatan Kota Surabaya dilakukan setiap sebulan sekali. Laporan yang diberikan meliputi:

1) FPPD surveilans aktif RS

2) Laporan kematian

3) Laporan indikator kinerja pelayanan

4) Laporan jumlah kunjungan

5) Laporan kematian bayi dan balita

6) Laporan kematian ibu

7) Laporan Px gizi buruk

8) Laporan kelahiran (persalinan)

9) Rekap lahir hidup

10) STP RI

11) W2 (laporan mingguan)

2. Kementrian Kesehatan RI melalui SIRS online dilakukan sebulan sekali. Laporan yang diberikan meliputi:

1) R.L 5.1 tentang pengunjung khusus rehabilitasi, hemodialisa, rawat jalan dan instalasi gawat darurat.

2) R.L 5.2 tentang kunjungan jalan

3) R.L 5.3 tentang 10 besar penyakit rawat inap

4) R.L 5.4 tentang 10 besar penyakit rawat jalan

E. Pelaksanaan Filling Berkas Rekam Medis Rawat Inap di Unit Rekam Medis Rumah Sakit Islam Jemursari Surabaya
Gambaran pelaksanaan penyimpanan data pasien rekam medis (filling) di RumahSakit Islam Jemursari Surabaya dengan menggunakan sistem desentralisasi. Desentralisasi adalah penyimpanan rekam medis pada masingmasing unit pelayanan. Terjadi pemisahan antara rekam medis pasien rawat jalan dan rawat inap.

Selain itu penyimpanan juga menggunakan sistem numerik (berdasarkan angka atau nomor) dengan sistem terminal digit. Sistem ini menggunakan nomor dengan 6 angka yang dikelompokkan menjadi 3, masing-masing terdiri dari 2 angka. Angka pertama adalah kelompok 2 angka yang terletak paling kanan, angka kedua adalah kelompok 2 angka yang terletak ditengah dan angka ketiga adalah kelompok 2 angka yang terletak paling kiri.

Masalah yang sering terjadi pada bagian filling berkas rekam medis rawat inap adalah lamanya waktu yang digunakan untuk mencari berkas rekam medis pasien yang sudah pernah melakukan rawat inap di Rumah Sakit Islam Jemursari. Hal ini disebabkan oleh berkas rekam medis belum tertata dengan rapi.

Retrival (pengambilan kembali berkas rekam medis) dengan menggunakan sistem outguide. Petunjuk keluar adalah suatu alat yang penting untuk mengawasi penggunaan rekam medis. Petunjuk keluar ini digunakan sebagai penggantian pada tempat rekam medis yang diambil dari rak penyimpanan dan tetap berada di rak tersebut sampai rekam medis yang diambil kembali.Berkas rekam medis dikatakan tidak aktif jika sudah melampaui batas waktu 5 tahun sejak terakhir pasien berkunjung. Berikut ini adalah flow chart dari assembling sampai dengan filling di unir rekam medis RSI Jemursari:

Rekam Medis di Ruangan 
JURNAL ILMIAH KESEHATAN MEDIAHUSADA ｜ＶOLUME 05/NOMOR 02/OKTOBER 2016

Sumber: Pedoman Pengorganisasian Unit Rekam Medis RSI Jemursari Surabaya Gambar 2 Alur Pengelolaan Rekam Medis di Rumah Sakit Islam Jemursari

\section{PEMBAHASAN}




\section{A. Pengolahan Data di Tempat Pendaftaran Pasien Rawat Inap di Rumah Sakit Islam Jemursari Surabaya}

Unit rekam medis menjadi salah satu pintu dalam pelayanan kesehatan di rumah sakit. Ruang lingkup unit rekammedis dimulai dari penerimaan pasien sampai dengan pelaporan informasi kesehatan. Tugas unit rekam medis mulai dari pengumpulan data, pemrosesan data sampai dengan penyajian informasi yang nantinya akan disampaikan ke pihak terkait sebagai bahan pertimbangan dalam pengambilan keputusan. Data yang dikumpulkan berupa data sosial yang berasal dari kartu identitas pasien dan data medis yang didapatkan selama pasien menjalani pemeriksaan dari tenaga kesehatan (Rustiyanto, 2010).

Menurut Markus (2010) proses registrasi pasien merupakan sumber data yang penting karena didapatkan sejak pasien pertama kali mendaftar yang menyangkut data diri dan status sosialnya. Hal ini sejalan dengan penelitian yang dilakukan oleh Hatta (2008) bahwa unsur informasi kesehatan harus berkualitas, salah satu ciri data yang berkualitas yaitu data bersifat akurat artinya data sudah dinilai kebenarannya. Pada pendaftaran pasien rawat inap di Rumah Sakit Islam Jemursari sudah menggunakan sistem elektonik sehingga memudahkan dalam proses pencatatan dan penyimpanan data pasien. Namun masih ada beberapa masalah terkait dengan pengelolaan data di TPPRI yaitu sering terjadi kesalahan penulisan tanggal pasien keluar rumah sakit (KRS) yang disebabkan perbedaan persepsi antara perawat ruangan dengan petugas yang ada dibagian keuangan (kasir).

\section{B. Pelaksanaan Assembling Berkas Rekam Medis Rawat Inap di Unit Rekam Medis Rumah Sakit Islam Jemursari Surabaya}

Bagian assembling yaitu salah satu bagian di unit rekam medis yang berfungsi sebagai peneliti kelengkapan isi dan perakit dokumen rekam medis sebelum disimpan.
Dokumen rekam medis yang telah diisi oleh petugas ruangan seperti dokter, perawat, dan petugas operasi. Lembar formulir dalam dalam dokumen rekam medis diatur kembali sesuai urutan riwayat penyakit pasien dan diteliti kelengkapan isi dokumen rekam medis. Fungsi dan peranan assembling dalam pelayanan rekam medis adalah sebagai perakit formulir rekam medis, peneliti isi data rekam medis, pengendali dokumen rekam medis tidak lengkap, pengendali penggunaan nomor rekam medis, dan formulir rekam medis.

Assembling sangat penting dalam memanajemen data agar data tersusun rapi dan akurat. Hal ini sejalan dengan Hatta (2008) bahwa unsur informasi kesehatan harus berkualitas, salah satu ciri data yang berkualitas yaitu data bersifat akurat artinya data sudah dinilai kebenarannya. Oleh karena itu proses assembling harus dilakukan dengan baik. Apabila proses ini dilakukan sekadarnya tidak sesuai dengan teori maka akan menimbulkan berbagai masalah dikemudian hari.

\section{Pelaksanaan Coding dan Indexing Berkas Rekam Medis Rawat Inap di Unit Rekam Medis Rumah Sakit Islam Jemursari Surabaya}

Kegiatan dan tindakan serta diagnosis yang ada di dalam rekam medis harus diberi kode dan selanjutnya diindeks agar memudahkan pelayanan pada penyajian informasi untuk menunjang fungsi perencanaan, manajemen dan riset bidang kesehatan. Kode klasifikasi penyakit oleh WHO (World Health Organization) bertujuan untuk menyeragamkan nama dan golongan penyakit, cidera, gejala dan faktor yang mempengaruhi kesehatan.

Menurut Depkes RI (1997) kecepatan dan ketepatan coding sangat bergantung pada pelaksana yang menangani rekam medis tersebut yang meliputi tenaga medis dalam menetapkan diagnosis, tenaga rekam medis sebagai pemberi kode dan tenaga kesehatan lainnya.

Setiap fasilitas kesehatan mengupayakan supaya pengisian rekam medis harus lengkap sesuai dengan 
peraturan yang berlaku untuk pengodean yang akurat diperlukan rekam medis yang lengkap coding harus melakukan analisis kualitatif terhadap isi rekam medis tersebut untuk menemukan diagnosis, kondisi, terapi, dan pelayanan yang diterima pasien (Hatta, 2008).

\section{PelaksanaanAnalisingdan Reporting BerkasRekamMedisRawatInap di Unit RekamMedisRumahSakit Islam Jemursari Surabaya}

Pelaporan rumah sakit dibuat untuk menunjang proses manajemen baik di tingkat lokal, wilayah maupun nasional. Semua data-data yang penting bagi masingmasing jenjang kepemimpinan perlu dilaporkan.Hanya masalahnya yang sulit dipecahkan adalah data yang bagaimana yang diperlukan yang dapat diperoleh dengan mudah tanpa beban tambahan penting untuk dilakukan suatu kondisi terpadu antara Dinas Kesehatan Provinsi Jawa Timur dan Kementrian Kesehatan RI untuk memformulasikan data yang perlu di laporkan sehingga tidak terjadi duplikasi yang tidak perlu. Perlu diperhatikan pula bahwa data yang dilaporkan harus singkat, jelas dan tepat waktu.

Menurut PMK No 1171 Tahun 2011 disebutkan bahwa setiap rumah sakit wajib melaksanakan Sistem Informasi Rumah Sakit (SIRS). Pelaporan SIRS terdiri dari pelaporan yang bersifat terbarukan setiap saat (updated) dan pelaporan yang bersifat periodik.

Pelaporan SIRS yang bersifat terbarukan setiap saat (updated) ditetapkan berdasarkan kebutuhan informasi untuk pengembangan program dan kebijakan dalam bidang perumahsakitan. Dalam hal ini RS Islam Jemurasri Surabaya sudah melakukan pelaporan yang terbarukan ini. Pelaporan biasanya dilakukan sebulan sekali yang diberikan kepada internal rumah sakit (Direksi RS) dan Dinas Kesehatan Kota Surabaya. Untuk formulir yang ada dilaporan tersebut seperti yang sudah dijelaskan pada bagian hasil.
Pelaporan SIRS yang bersifat periodik dilakukan dua kali dalam satu tahun. Untuk laporan periodik RS Islam Jemursari Surabaya hanya melakukan sekali dalam setahun yang akan dikirim ke Kementrian Kesehatan melalui SIRS online. Namun yang bertanggungjawab dalam laporan ini yaitu bagian kesekretariatan. Unit rekam medis sendiri hanya melakukan pelaporan terbarukan yang dilakukan sebulan sekali.

\section{E. Pelaksanaan Filling Berkas Rekam Medis Rawat Inap di Unit Rekam Medis Rumah Sakit Islam Jemursari Surabaya}

Filling merupakan salah satu bagian dalam unit rekam medis.peran dan fungsi dalam pelayanan rekam medis yaitu sebagai penyimpan BRM. Bagian ini biasanya dilakukan setelah coding dan menjadi proses terakhir dalam proses pengolahan berkas rekam medis. Penyimpanan BRM dilakukan untuk melindungi arsip-arsip BRM terhadap kerahasiaan isi data rekam medis dan pelindung arsip-arsip BRM terhadap bahaya kerusakan fisik, kimiawi dan biologi.

Menurut penelitian Jogiyanto (2005) menyatakan bahwa kualitas dari suatu informasi salah satunya yaitu tepat pada waktunya yang berarti informasi yang datang pada penerima tidak boleh terlambat sebagai landasan dalam pengambilan keputusan. Sedangkan menurut WHO (1992) untuk mengontrol semua informasi medis pasien yang baik harusnya disimpan di satu folder. Hal ini dilakukan untuk memudahkan dalam pengendalian informasi karena disimpan dalam satu tempat.

Hal ini disesuaikan dengan ruang penyimpanan yang ada di setiap rumah sakit. Menurut Permenkes No. 269/MENKES/PER/III/2008 tentang rekam medis bahwa rekam medis untuk sasaran saranan pelayanan kesehatan non rumah sakit wajib disimpan sekurang-kurangnya untuk jangka waktu dua tahun terhitung dari tanggal terakhir pasien berobat.

Pada umumnya rekam medis dinyatakan tidak aktif apabila selama 5 
Analisis Sistem Pengelolaan Rekam Medis Rawat Inap ... | RIZQIYAH

tahun terakhir rekam medis tersebut tidak digunakan lagi. Apabila tidak tersedia tempat penyimpanan rekam medis aktif, harus dilaksanakan kegiatan menyisihkan rekam medis seirama dengan pertambahan jumlah rekam medis baru dan pada saat diambilnya rekam medis tidak aktif, di tempat semula harus diletakkan tanda keluar untuk mencegah pencarian yang berlarut-larut pada saat diperlukan. Rekam emdis yang tidak aktif disimpan di ruang bagian rekam medis atau dibuat microfilm. Jika diganakan microfilm rekam medis aktif dan tidak aktif dapat disimpan bersamaan, karena penyimpanan microfilm tidak banyak memakan tempat (Dep. Kes, 1991).

\section{SIMPULAN DAN SARAN}

Dari hasil penelitian didapatkan bahwa masih terdapat masalah mulai dari sistem pendaftaran pasien rawat inap sampai dengan pelaksanaan filling berkas rekam medis rawat inap di Unit Rekam Medis Rumah Sakit Islam Jemursari Surabaya. Perlu adanya peningkatan komitmen dari seluruh tenaga medis baik itu dokter, perawat maupun tenaga kesehatan lainnya untuk mengisi rekam medis dengan lengkap dan tepat waktu. Selain itu, data rekam medis lebih dikelola dengan baik sehingga memudahkan pada saat data dibutuhkan sewaktu-waktu.

\section{SARAN}

1. Mengintegrasikan informasi mengenai ketersediaan kamar untuk setiap ruangan kedalam Sistem Informasi Rumah Sakit (SIRS) sehingga memudahkan petugas di TPPRI

2. Menerapkan sistem poin kepada tenaga medis yang tidak mengisi rekam medis dengan lengkap

3. Mengadakan pertemuan secara rutin antara petugas ruangan dan petugas rekam medis terkait masalah kelengkapan berkas rekam medis agar tidak terjadi kesalahpahaman
4. Membuat aplikasi online terkait berkas rekam medis rawat inap agar memudahkan proses pelaporan

5. Lebih mengoptimalkan kegunaan dari rekam medis, tidak hanya untuk fungsi dokumentasi tetapi untuk fungsi lainnya sesuai CIALFREDS

\section{DAFTAR PUSTAKA}

Departemen Kesehatan RI. (1991). Petunjuk Teknis Penyelenggaraan Rekam Medis / Medical Record Rumah Sakit. Jakarta : DEPKES RI.

Depkes RI. (1994). Buku Pedoman Pencatatan Kegiatan Pelayanan Rumah Sakit di Indonesia. Jakarta: Dirjenyanmed

Depkes RI. (1997). Pedoman Pengelolaan Rekam Medis Rumah Sakit di Indonesia.Jakarta: Dirjenyanmed

Fajri, Erick. (2008). Filling System Rekam Medis. filling system rekam medis.pdf

Hatta, G.R. (2008). Pedoman Manajemen Informasi Kesehatan Di Sarana Pelayanan Kesehatan. Universitas Indonesia

Jogiyanto HM. (2007). Sistem Informasi Keperilakuan. Yogyakarta: ANDI

Peraturan Menteri Kesehatan Republik Indonesia Nomor 749a/MENKES/PER/XII/1989 tentang Rekam Medis. Menkes RI. Jakarta

Peraturan Menteri Kesehatan Republik Indonesia Nomor 377/MENKES/PER/III/2007 tentang Standar Profesi Perekam Medis.Menkes RI. Jakarta

Peraturan Menteri Kesehatan Republik Indonesia Nomor 269/MENKES/PER/III/2008 tentang Rekam Medis. Menkes RI. Jakarta

Peraturan Menteri Kesehatan Republik Indonesia Nomor

1171/MENKES/PER/VI/20

11 tentang Sistem Informasi Rumah Sakit. Menkes RI. Jakarta 
JURNAL ILMIAH KESEHATAN MEDIAHUSADA ｜ VOLUME 05/NOMOR 02/OKTOBER 2016

Shofari, Bambang. 2004. Pengelolaan Sistem Rekam Medis

Kesehatan. Semarang

Suryo Nugroho Markus. (2010). Rancangan

Database dalamPengembangan

Rekam Medis Elektronik Rawat Jalan di Rumah Sakit Panti Rapih Yogyakarta

Rustiyanto, E,. (2010). Statistik Rumah Sakit Untuk Pengambilan Keputusan. Cetakan pertama, Graha Ilmu, Yogyakarta 